\title{
Redefinitions of India and Individuality in Adiga's The White Tiger
}

\author{
Kathleen Waller \\ University of Hong Kong
}

Follow this and additional works at: https://docs.lib.purdue.edu/clcweb

Part of the Comparative Literature Commons, and the Critical and Cultural Studies Commons

Dedicated to the dissemination of scholarly and professional information, Purdue University Press selects, develops, and distributes quality resources in several key subject areas for which its parent university is famous, including business, technology, health, veterinary medicine, and other selected disciplines in the humanities and sciences.

CLCWeb: Comparative Literature and Culture, the peer-reviewed, full-text, and open-access learned journal in the humanities and social sciences, publishes new scholarship following tenets of the discipline of comparative literature and the field of cultural studies designated as "comparative cultural studies." Publications in the journal are indexed in the Annual Bibliography of English Language and Literature (Chadwyck-Healey), the Arts and Humanities Citation Index (Thomson Reuters ISI), the Humanities Index (Wilson), Humanities International Complete (EBSCO), the International Bibliography of the Modern Language Association of America, and Scopus (Elsevier). The journal is affiliated with the Purdue University Press monograph series of Books in Comparative Cultural Studies. Contact: <clcweb@purdue.edu>

\section{Recommended Citation}

Waller, Kathleen. "Redefinitions of India and Individuality in Adiga's The White Tiger." CLCWeb: Comparative Literature and Culture 14.2 (2012): <https://doi.org/10.7771/1481-4374.1965>

This text has been double-blind peer reviewed by $2+1$ experts in the field.

The above text, published by Purdue University Press (CPurdue University, has been downloaded 10910 times as of $11 / 07 / 19$.

This document has been made available through Purdue e-Pubs, a service of the Purdue University Libraries. Please contact epubs@purdue.edu for additional information.

This is an Open Access journal. This means that it uses a funding model that does not charge readers or their institutions for access. Readers may freely read, download, copy, distribute, print, search, or link to the full texts of articles. This journal is covered under the CC BY-NC-ND license. 


\title{
PURDUE
}

CLCWeb: Comparative Literature and Culture
\[ \]

ISSN 1481-4374 <http://docs.lib.purdue.edu/clcweb> Purdue University Press @Purdue University

CLCWeb: Comparative Literature and Culture, the peer-reviewed, full-text, and open-access learned journal in the humanities and social sciences, publishes new scholarship following tenets of the discipline of comparative literature and the field of cultural studies designated as "comparative cultural studies." In addition to the publication of articles, the journal publishes review articles of scholarly books and publishes research material in its Library Series. Publications in the journal are indexed in the Annual Bibliography of English Language and Literature (Chadwyck-Healey), the Arts and Humanities Citation Index (Thomson Reuters ISI), the Humanities Index (Wilson), Humanities International Complete (EBSCO), the International Bibliography of the Modern Language Association of America, and Scopus (Elsevier). The journal is affiliated with the Purdue University Press monograph series of Books in Comparative Cultural Studies. Contact: <clcweb@purdue.edu>

\begin{tabular}{c} 
Volume 14 Issue 2 (June 2012) Article 12 \\
Kathleen Waller, \\
"Redefinitions of India and Individuality in Adiga's The White Tiger" \\
<http://docs.lib.purdue.edu/clcweb/vol14/iss $2 / 12>$ \\
\hline Contents of CLCWeb: Comparative Literature and Culture 14.2 (2012) \\
Thematic Issue New Work in Comparative Indian Literatures and Cultures \\
Ed. Mohan G. Ramanan and Tutun Mukherjee \\
<http://docs.lib.purdue.edu/clcweb/vol14/iss $2 />$
\end{tabular}

\begin{abstract}
In her article "Redefinitions of India and Individuality in Adiga's The White Tiger" Kathleen Waller discusses Indian individualism as being supported by a democratic and secular society, but also stymied by traditions and socioeconomic realities which keep most of its people living in poverty. In The White Tiger, Adiga challenges Indian culture to create a society in which individuals are truly free. Waller argues that the relevance of Adiga's novel is that it is social structure and practices of hierarchy keep many people in the lower classes of Indian society and that this state of affairs is counter productive. Instead, Adiga's novel suggests that the situation of India's social structure and its entrenched hierarchy would have to be looked at and that through the erasure of constraint by society's class hierarchy Indian society could transform itself.
\end{abstract}




\section{Kathleen WALLER}

\section{Redefinitions of India and Individuality in Adiga's The White Tiger}

Aravind Adiga's novel The White Tiger challenges definitions of Indian identity with a narrator who comes from a nameless and birthday-less past with a written fate as a member of the lower caste. The servant rises in power by using the very nothingness he comes from as an advantage and addresses his agenda to China's premier. The narrator becomes something in not only Indian but also global society under the symbolic pseudonym of "The White Tiger" as he appeals to China and speaks with understanding of the United States and world economies. Despite a lack of formal education, he knows multiple religions and languages as well. The fact that the narrator is also a murderer is not excusable but shows the reader that the embrasure of nothingness in India is not fully possible at this time. Therefore, Adiga is both asking Indians to veer away from their fated paths while also changing economic, political, and social policies. There must be a way for individuals within society to seek redefinition through both lawful and ethically correct means. The concept of an empowering nothingness is an inherent concept of literary deconstruction in Jacques Derrida's "Différance." Derrida's play on the French differer, meaning both "to differ" and "to defer," allows for a link in "signif[ying] nonidentity" and "the order of the same" (385). Differance with an "a" becomes a philosophy rather than a simple word. The neologism "indicates the middle voice" (385), thereby asking the reader to allow dissonant suspensions of known truths defined by societies. Individuals' free will is not just an action here, but a state of being and the ability to change what one's being is defined as. Nonidentity becomes a form of empowerment.

In The White Tiger Adiga is first defined through nonidentity by the fact that he has "never been given a name" (10) nor "know[n] his exact age" (12). He has always been called "Munna," or "boy," which his teacher claims is "not a real name" and subsequently names him "Balram ... the sidekick of the god Krishna" (10-11). Although there is consideration through the novel of the narrator's place in society that is dependent on his position in India's caste system, his lack of name challenges a strict fate through its potential for mutability. The teacher already challenges the notion that we are born into identities by labeling Munna with the new name of Balram and tells Balram that his own name is Krishna, therefore placing Balram as his "sidekick" in the classroom. The new name may be a step up from "boy" in the hierarchy, but a "sidekick" is not only below another by definition but also at the mercy of the other's fate. "Balram" is an elevated status of a name with less freedom of identity. However, Balram's father seems to have no care what his son is called: "'If it's what he wants, then we'll call you that'" (11). He does not attempt to design Balram's fate, and we are suddenly aware that the narrator need not be caught in the continuous cycle of father and son that dominates class definitions worldwide.

Nonidentities in literature, especially through nameless or multiply named characters, have been precursors to actual social changes in the past. Ralph Ellison's nameless narrator in Invisible Man preceded the Civil Rights Movement in the United States (on Ellison, see, e.g., Bourassa). The often "complex" and "ambiguous" novel creates "an alternative basis for African American social struggle after the Brotherhood experience, its continuing (if muted) affirmation of possibilities for social reform, and its forecast of the actual content of civil rights actions in the decades after its publication" (Hobson 355). Like Adiga, Ellison does not spell out a solution for US-America's race problems in the 1960s. Instead, he focuses on individuals and the energy that can be created through abstraction. Adiga references his book as a general influence in his writing, while remarking that "as a writer, [he] do[es]n't feel tied to any one identity" (284). Adiga himself has deconstructed style and authorship through self-discovery of his artistic purpose and fthis reason he feels comfortable with an elusively defined narrator as in Ellison's novel. Similarly, Dai Sijie gives us two somewhat unnamed characters in Balzac and the Little Chinese Seamstress, although the novel is in retrospect rather than an actual precursor of the Chinese Cultural Revolution feigns a foreshadowed political breakdown of naming to show what one may still do to seek inverted power in communist China. Sijie's narrator's name is only briefly mentioned in Chinese $(\mathrm{Ma})$ and is unused otherwise in the text. Both he and the unnamed "Little Seamstress" go through changes in their understandings of themselves and society. The narrator has been stripped of his bourgeois status and connection with his family, allowing him to see 
the world from a new perspective. The Little Seamstress is given a window into the intellectual world as she begins reading literature and eventually running away from her village. Adiga's narrator is also displaced and family-less when he begins a journey of redefining himself and often focuses on knowledge as a source of hope. As Derrida does through examinations of literature, these characters "order [them]selves by the disorder that is produced" (387). Dissonance is essential to their growth and our understanding for the potential of a population's growth at the individual level. India's efforts to fully achieve a democratic and secular society emphasize and encourage this growth.

The concept of representing nonidentity through a naming and lack of naming to promote societal growth is also present in Virginia Woolf's A Room of One's Own. Her manner of focusing on nothing as something, while also choosing arbitrary names for her female narrator and examples, show an uncanny precedence, to which Adiga's writing becomes a resemblance. Like Ellison's novel, Woolf's essay predates many changes in women's rights. Woolf changes the conventions of writing to illustrate that she prefers to have a nonidentity as a writer. As a woman, she is able to break from what the patriarchy of writing has determined to be correct (on the situation of women in India, see also, e.g., Chanda; Sharma; Turner). She begins her text with a conjunction and a question while addressing the reader directly. During the 1920s, this format straying from tradition would upset most readers and scholars. She tells us what she will conclude, namely that she "shall never be able to come to a conclusion" (3). However, it is the lack of convention that is her point. As she writes, she even tells us that she "will take the liberty to defy ... convention" (10). Her fresh writing style takes the reader immediately to the "occult zone of a nonknowing" (Derrida 388), where we must find the answers ourselves. This "zone" in the form of a dissonant state of being is named as "murmuring" by Woolf: "Nothing was changed; nothing was different save only here I listened with all my ears not entirely to what was being said, but to the murmur or current behind it" (12). Woolf refers here to poetry written after World War I, although it may contain similar subject matter and figurative language as before. Because the difference is difficult to grasp, it takes further thinking, in the method of différance, on the part of the reader to understand it: the absence of thought or physical "change" in the form of "nothing" creates a vibration like a brain wave that eventually leads to truth and the creation of an individual's identity.

Adiga, too, catches us off guard by challenging the conventions of writing, even for the postmodern era. He begins his novel with the narrator addressing the actual current premier of China in a letter, which becomes the entire book. It is already unusual to write a novel to a living being, even subversively. The narrator writes with directness and humor, relating himself to the premier. All conventions of careful respect for a national leader are ignored as the narrator says he "consider[s] [him]self one of your kind" to the premier (2). Perhaps this connection with a leader of a communist country is also a way to seek out political ideologies he feels may work for India. In the true definition of communism, this narrator, no matter what his caste, should be free from hierarchy and therefore equal to the social class of the premier. However, the reader knows that even a communist premier would see himself as higher and removed from the rest of society. Adiga thereby mocks the notion that communism could be a true answer and that there is any hope the premier would even listen to the story of this young man. At the same time, Adiga has the chance to reach global recognition through his literature, while his narrator cannot. In this way, he may reach many of the world's political leaders with his strong yet fuzzy message. We are startled time and time again by his blunt approach, as well as far-reaching statements about economics, politics, and religion. With the added confusion of knowing pieces of his story from the beginning, the narrator creates the same "murmur" or space for different understanding as Woolf's essay did eighty years ago.

The method of naming in Wolff's and Adiga's texts functions as a defiance of convention with similar murmuring effects. Woolf's narrator allows the audience to call her whatever it wants: "call me Mary Beton, Mary Seton, Mary Carmichael or by any name you please - it is not a matter of any importance" (5). Her indifference parallels Balram's easy acceptance of others' arbitrary name for him. Woolf goes further in creating an educational institution that is in the middle of Oxford and Cambridge universities. Its name, Oxbridge, is a space for newly interpreting old traditions in writing, gender identity, and education. Both her own dynamic name and conglomerated educational institution allow Woolf to avoid being "locked in" to convention and patriarchal traditions (24). She gives us symbolic representation of this space that is also her mind through the room she seeks, an aquarium, and the 
gates of the library. She demonstrates a lack of access to money, tradition, and man's world by these spaces. However, in the end, weighing the pros and cons of being "locked in" or "locked out" from patriarchal society and British traditions, Woolf finds herself under a beautiful starry sky thinking, "One seemed alone with an inscrutable society" (24). Although a man of tradition may find this scene to be frightening, it can also be an opportunity for deeper understanding and a redefinition of self. Woolf embraces nonidentity at this moment, plunging herself into the universe as an individual rather than as a member of her society.

Adiga's narrator reaches this space also metaphorically while simultaneously taking us on a literal journey. His metaphor for the cage society has placed him and the lower classes into the rooster coop, a busy spot in the marketplace: "The roosters in the coop smell the blood from above. They see the organs of their brothers lying around them. They know they're next. Yet they do not rebel. They do not try to get out of the coop. The very same thing is done with human beings in [India]" (147). The narrator tells us that all poor Indians act the same way in that they are stuck in a disgusting situation that they will not leave. They may even see close opportunities, like a "suitcase sitting on a backseat ... [with] two million rupees; more money than that chauffeur will see in his lifetime" (148). But because they are part of the rooster coop, they will not take advantage of the careless mistakes of the upper castes. The people locked in are the extremely poor servants, "millions [who] wake up at dawn - stand in dirty, crowded buses - get off at their masters' posh houses - and then clean the floors, wash the dishes, weed the garden, feed their children, press their feet - all for a pittance" (149). The physical space of the car surrounding the chauffeurs echoes the cage mentality, acting even as a more extreme wall that does not allow for the transference of sound. Freedom of thought, profession, money, and time are never accessed by these millions. Their time is filled up by tasks within society's definition of them. The narrator asserts that if a servant were to try to break from the coop, by stealing or disobeying someone from the higher social class, he must be "prepared to see his family destroyed - hunted beaten and burned alive by the masters" (150). Therefore, servants force their yearnings for freedom and independence to their unconscious minds and cease to be anything of consequence. However, they lack the ability to become a powerful form of nothingness within their defined roles in society. It takes an anomaly, or a rare "White Tiger" that the narrator is eventually able to morph into, to break from this meaningless, and paradoxically defined, position in society. Although he faces the possibility of prison, his existence in the confines of a basement room and master's car are already not far off.

White tigers are rare and "only a dozen or so have been found in the wild" ("The Secret" 26). These mutations of the Bengal tiger are inbred in zoos, have led to a larger population in captivity than in the wild, and forced breeding and caged concrete habitats make the lives of such kingly animals meaningless like Adiga's description of poor servants in India. Balram first has an encounter with a white tiger at the National Zoo in New Delhi: he notices the sign that reads: "Imagine yourself in the cage" (150). This moment comes when Balram is about to take the fall for a hit and run one of his masters commits that kills a poor unidentified Indian on the street. He is anticipating jail time for the rest of his life, much like the tiger in front of him and can easily imagine an existence in the cage. He remarks that he "can do that with no trouble at all" (150), while likening his entrapment again to that of being in the rooster coop. Balram is not ready to see a way out of the cage, much like Woolf's character sees no way into the library containing "treasure" and must continuously attempt to "trespass[]" her way through male academic institutions (6-7). However, she later is able to speak of ideas and moments which are "for ever coming alive in [her] mind" (19). She passes beyond the reality that is handed to her in using her imagination and thought to reach happiness and success. We know that Woolf was indeed able to reach success in her literary pursuits but happiness for her was a constant battle (see, e.g., her own A Writer's Diary). Her eventual suicide may show that the lingering of patriarchal entrapment kept her from fully realizing a release from her cage: if "difference fails to be accounted for" we find "absolute loss, with death" (Derrida 400). Balram also fights his existence, showing that he is aware of his unconscious self and realizing a possibility to make his social status dynamic. He first must realize that he can vanish, for he has no real name or birth date, no official records with the government, no consequence to anyone if his master is no longer alive. Instead of killing himself like Woolf, Balram kills his master. The white tiger at the zoo again connects with Balram's unconscious self: "It turned its face to my face. The tiger's eyes met my eyes, like my 
master's eyes have met mine so often in the mirror of the car. All at once, the tiger vanished" (237). Balram realizes that he, too, can escape the cage of the rooster coop by becoming invisible to society's constraints. He can simply ignore the definition of himself that his birth and his country have given him. The tiger's disappearing act prompts Balram to take the ultimate plunge by murdering his master, stealing "seven hundred thousand rupees" (241), and running away to Bangalore. Balram embraces the nothingness that he is in order to become somebody with money and power.

Derrida recognizes that his definition of self is nothing that can be defined by the physical world or society. He explains the "difference between Beings and beings," where the capital B demonstrates an awareness of the unconscious self, "the first consequence of this is that differance is not. It is not a being-present, however excellent, unique, principal, or transcendent one makes it. It commands nothing, rules over nothing, and nowhere does it exercise any authority" (401). Because no one can define our différance, we are free to let it become Being without acceptance from government or society. Balram takes the white tiger's identity as his new name, thereby creating a free identity from the same animal that enslaved. The paradox is extended in the equation of the tiger with Balram's master: although the master enjoys a life in the upper caste of society, his defined role does not allow for true Being. The layered paradoxes in the text begin to function like the space inside of an enso. Adiga frequently uses the word "nothing" to give it a definition like that of space. This tool gives an even stronger connection to Chinese culture, specifically Zen Buddhism, which may allow the premier to understand better the plight of India's people. enso are filled with paradoxes and opposites, containing everything and nothing, the moon and the sun, light and dark, and knowledge and ignorance all in one. Stephen Addiss describes it as "the all, the void, and enlightenment itself" (12). The white space of the inner circle can be absent or present, often described as "void of whole." White symbolism pervades the text and is confused by a multicultural reading of it. Whereas in Western cultures white is seen as a representation of innocence and purity, Asian cultures link white with death and ominous feelings. Asian texts also lack the immediate connotations of race with white that Western society might place on it, especially when looking at the concepts of white and black together. Whiteness as a race only enters the novel once during a conversation about paying for prostitutes when another driver says, "White skin has to be respected" (193). There is a fascination with skin color that is different, much like the fur of the white tiger. Here, the white skin costs a premium and attracts customers (just like at the zoo), but the prostitute remains a trapped being.

Contemporary Indian artist A. Balasubramaniam uses whiteness as a paradox in his work. Many visual artists see white as a void of color: any pigment on a brush will discolor the white paint. However, Balasubramaniam views white much like a chemist or physicist: " it is the closest colour to light, and we all know that light has all the colours" (Sand 4). His traces of people through white sculptures show the "visible/invisible ... making the viewers aware of what they are missing in normal life" (Sand 4). People are asked to focus on their différance or the invisible wavelengths that make up white light. His white trace-like sculptures allow viewers to transpose themselves in the structure and understand the power of nonidentity. They can begin to understand what emotions and pieces of true identity lie in the hidden space between everyday reality and true Being. In comparing the work of Balasubramaniam with Adiga's, we start to sense a global dialogue that Indian artists are using to connect with the rest of the world. Unity through undefined messages cause others to think more deeply in making sense of these motifs like whiteness.

After Balram's first encounter with the white tiger, we begin to see some of the rage that lies within his surface of différance. Milk, which usually connotes nurturing and innocence, becomes the liquid white symbol of his anger: I watched the milk. It seethed, and spilled down the sides of the stainless steel vessel; the small, shrunken man smiled - he provoked the boiling milk with a spoon it became frothier and frothier, hissing with outrage" (214). Milk holds Balram's unconscious as he looks on it, but he is not ready to define it and make it fully visible until he decides an escape route. It is a reminder that Balram has a second underlying consciousness, which is also ready to explode in "outrage." The same subconscious self understands that it must take drastic measures to seek the freedom it yearns for. It knows deep down that the nothingness Derrida prescribes is necessary for his success. Hints that he knows are within the language of the text. The growing link toward the white tiger and whiteness is one way we see his deeper knowledge leak into the text. The repetition of the word "nothing" itself also shows a meaning through absence. It reminds us through a void that the 
millions of unnamed or lost people of India have unconscious beings that are kept in nothingness by society and government. We cannot blame the people for not taking advantage of their "nothing" status as Balram does, because he must kill a man to succeed. The word appears over thirty times in the text, often set off in short separated sentences or used as complete sentences. From the beginning, "nothing" is equated with the geographical and societal position that Balram is born into. He calls this space the "Darkness" (11), a place absent of knowledge or the chance for enlightenment on any level. As his dead mother is placed in the "black mud" of the Ganga river, he states, "Nothing would get liberated here" (15). He faints at this moment as he does later in front of the white tiger's cage. Fainting seems to bring him closer to the realm of anti-being as a metaphorical death, where he can then reshape himself into any Being he chooses.

Before heading to Delhi as a chauffeur, Balram is first named as a "white tiger" by an inspector who notes his intelligence (30). However, the name does not stick at this point because his intelligence does not empower him. Instead, it creates jealousy and a need by others to keep Balram in his place within society. The word "nothing" is again used referring to his frustration although it does not yet explode like the later symbolic milk. His less intelligent older brother, Kishan, takes him out of school one day and says "nothing" to explain where they are going (31). Balram is taken to a shop to break coal, one of the lowliest and intelligence lacking jobs he can imagine. As some of the schoolboys come around and poke fun at him, Balram states twice "I said nothing" (32). He is coming closer to an awareness that he is not satisfied with his position in society and that an internal change, rather than voiced response to the boys, is necessary to leave. He is frustrated throughout the novel with his "half-baked" education with "half-formed ideas" (8) when seeks knowledge and later "feel[s] a kind of electricity buzzing up" when he is "standing around books" (175). Woolf similarly struggles as her thoughts are eaten up by the guards of the university while she attempts to allow her mind to wander. Although she uses the metaphor of catching a fish for discovering an idea, "the sudden conglomeration of an idea at the end of one's line" (5), her "little fish" is sent "into hiding" (6). On the traditional male campus she is cut off from individual freedom. Balram's knowledge gained in school is sent into hiding when he is first asked to break coal and later when he is given a full time position as chauffeur. However, his fluency in English, ability to start his own company with the money he steals, knowledge of religions, and understanding of both foreign nations of China and the U.S. are all demonstrated throughout the novel and show the reader that any of the hundreds of millions of Indians who are "half-baked" by education may nonetheless carry great intelligence within them.

The above theme is echoed in the recent Indian film success, Slumdog Millionaire, in which an orphaned boy from the slums makes a fortune on a popular game show. He wins not by chance but by his own intelligence as he answers questions. His knowledge is based on intuition, education, and experience and the nothingness that he came from is what makes him into a popular star. Beggars on the street pray for him to win, perhaps seeing a bit of themselves in this young man. Balram has found his way similarly into money from a "bottom caste" in which he was taught to ask for "absolutely nothing" in payment from his employer (55). The lack of entitlement to money is a significance rather than a void. Its absence from many lives should be the subject of discussion by political leaders. Later, when Balram is weighing whether or not he should murder his employer, he notes that although he makes 4,000 rupees a month, he saves "nothing" (210). The servant and eventual chauffeur job do pay, but it is essentially "nothing" in that the money would never be enough to save for property or travel or a change in socioeconomic status. The status is viewed more permanently through India's caste system than a status in the U.S. where ideals of the "American Dream" are a hope if not a reality. Balram is fascinated by the U.S. and appreciates its secularism, capitalism, and democracy, but notes that India, too, has these ideologies in place. The problem is that they have not reached all people as they should. Although the United States also has a large poverty problem and people who are discriminated against for religious beliefs, the scale is much smaller. The government has an easier time preventing religious attacks and giving aid to the poor owing to a more strongly established infrastructure of government. In The White Tiger US-America is a symbolic dream rather than a country to emulate and Balram equates this possibility to himself, ignoring traditions of India's caste system. However, it is harder for government to define and give rights against discrimination to lower castes. When the U.S. created anti-discrimination laws for African Americans during the Civil Rights Movement, people with more clear definitions as minorities 
could be given legal rights. The fact that most people of different races look differently from each other allows the government to step in and help. With the caste system of India, there is empowerment in being able to lack definition as a particularly different race, but it also makes it more difficult to overtly help certain groups of people who are unaccounted for. Therefore, it becomes the individual's burden or opportunity to take advantage of this mutability.

If an individual of lower caste is to mutate his/her existence, he/she must choose an established existence to inhabit. Balram finds a fitting niche in the space his employer holds. Although Balram's boss Mr. Ashok is "smart" enough to pick up on important changes within India's social and economic network, he unknowingly gives Balram the final push toward the very bottom of nothingness, therefore causing the servant to seek a switching of places with his employer. Ashok speaks of his yearning for the simple life of servants without realizing that his servant has planned to switch places. He talks of the wonderful food that they eat and how they have such a strong sense of family. The problem is that for Balram to become "(in a sense) his master" (39), he must kill him. Balram is surrounded by death as a child and then has deathlike fainting spells as he closes in on nothingness. For him to make a full switch to master status, Ashok must take the full step to death. He lacks the ability to seek his differance, which we see as he never fully understands Balram, and so his nonidentity is also a non-being. His "différance fails to be accounted for" and he succumbs to "absolute loss, with death" (Derrida 400). If Ashok had been able to understand more deeply the difference between his place in society and Balram's, he may have been able to change enough (higher wages, better living space, or more freedom of time) to keep Balram from killing him. However, his failure to fully embrace the beauty and intelligence in Balram, who is also a part of his nation and culture, is what ceases his existence.

The final push follows a chain of events beginning with Ashok's wife accidentally killing a nameless poor person on the road. Ashok's less-humane partner suggests that Balram take the fall for the crime, so that they will "have nothing to worry about" (142). The calmness that Ashok exhibits at this suggestion forces Balram into an even deeper frenzy of despair and anger. While the charges are quickly dropped, Balram's anger lingers and intensifies when Ashok seeks support after his wife leaves him. Instead of making noise and visible emotion, Balram retreats into quiet nothingness. In the ensuing narrative sounds and doings of "nothing" are echoed. Balram comes to the door for "'nothing, Sir'" and Ashok says "nothing about" his previous unfair treatment toward Balram (157). Even Ashok feels that he is "absolutely nothing" because of the lack of family in his life (161). Balram questions "the point of living?" (159) and this allows him to realize he does have a point if he can only switch places. It is more evident that Ashok's being merely dissolves, because "master and driver had somehow become one body that night" (169), although this is during a night before the murder. When Balram finally does kill his master by the roadside, he proclaims immediately that he is "a free man" (246). The plot speeds up quickly and we find Balram as the boss of a successful entrepreneur in Bangalore. Instead of being a chauffeur, he owns cars and has drivers who work for him. The police even answer him. Now using his employer's name and the added pseudonym of "The White Tiger," Balram transcends the social, economic, and political status he was born into.

Suddenly towards the end of the novel, both "everything" and "nothing" are played against each other, like the paradox in an enso, in a series of altered reality, nightmare, and dream. In a sentence separated by paragraphing, the narrator states, "The difference is everything" in reference to the way he can now "complain about the police" as a "rich" man (266). Because he now has money and power, someone someday may listen to him. Perhaps even the prime minister of China will pay attention to his message. Although Balram recognizes murder as wrong, he finds the "real nightmare" to be if he never had the nerve to kill Ashok (269). There is no guilt for his crime, because he sees murder as the only way to realize his Being. He also has a dream to "sell everything, take the money, and start a school - an English language school - for the poor children in Bangalore" (275). Balram furthers his definition of Being by showing his altruistic side. However, as he thinks further about this dream, he proclaims that "all this dreaming I'm doing - It may well turn out to be nothing" (275). The state of India's government and society may not allow him to do something so altruistic. This constant shift from everything to nothing and reality to dreams and nightmares shows that The White Tiger continues to be cognizant of différance. Sudden success has not stopped Balram from getting in touch with his Being. The fact that he writes to the Chinese premier shows he wants more to happen for his 
country. His thoughts of starting a school also show a positive dynamic quality. However, he is entrenched in corruption with the police and his workforce. Balram's last pronouncement is that he is "ready to have children," but he negates it with a final "Ha!" (276). He knows that changes are still needed in India for future generations.

In conclusion, Balram's story is relevant to India's current state of affairs and its hierarchical society despite attempts to institute change. It is unclear what, exactly, Balram would like the Chinese premier to do. However, we gain awareness of a lost people with great potential to change Indian culture: the relevance of Adiga's The White Tiger and its narration of Balram's lack of education and his story or the same in the film Slumdog Millionaire or that of rural peasants in Sijie's novel is that the lack of education paired with entrenched social hierarchy holds large numbers back from becoming dynamic individuals.

\section{Works Cited}

Addiss, Stephen. The Art of Zen. New York: Harry N. Abrams, 1989.

Adiga, Aravind. The White Tiger. New York: Free P, 2008.

Bourassa, Alan. "Affect, History, and Race and Ellison's Invisible Man." CLCWeb: Comparative Literature and Culture 8.2 (2006): <http://docs.lib.purdue.edu/clcweb/vol8/iss2/8/>.

Chanda, Ipshita. "An Intermedial Reading of Paley's Sita Sings the Blues." CLCWeb: Comparative Literature and Culture 13.3 (2011): <http://docs.lib.purdue.edu/clcweb/vol13/iss3/12>.

Derrida, Jacques. "Différance." Trans. Alan Bass. Literary Theory: An Anthology. Ed. Julie Rivkin and Michael Ryan. London: Blackwell, 1998. 385-407.

Ellison, Ralph. Invisible Man. New York: Vintage, 1995.

Hobson, Christopher Z. "Invisible Man and African American radicalism in World War II." African American Review 39.3 (Fall 2005): 355-76.

Sand, Olivia. "Asian Art Profile: A. Balasubramaniam." Asian Art (October 2008): 2-4.

"The Secret of the White Tiger." National Geographic 304 (2000): 26-27.

Sharma, Narinder K. "Duality of Illusion and Reality in Desai's In Custody." CLCWeb: Comparative Literature and Culture 14.2 (2012): <http://docs.lib.purdue.edu/clcweb/vol14/iss2/9>.

Sijie, Dai. Balzac and the Little Chinese Seamstress. London: Vintage, 2006.

Slumdog Millionaire. Dir. Danny Boyle. Hollywood: Fox Searchlight Pictures, 2008.

Woolf, Virginia. A Room of One's Own. New York: Harcourt, 1989.

Turner, Elen. "Gender Anxiety and Contemporary Indian Popular Fiction." CLCWeb: Comparative Literature and Culture 14.2 (2012): <http://docs.lib.purdue.edu/clcweb/vol14/iss2/13>.

Woolf, Virginia. A Writer's Diary. 1940. New York: Harcourt, 1982.

Author's profile: Kathleen Waller is working towards her Ph.D. in comparative literature at the University of Hong Kong. Her fields of interests in research include US-American, African American, and Victorian literature, drama, queer studies, deconstruction, psychoanalytic theory, film studies, and comparative studies with French, Italian, Japanese, and Hong Kong texts. Waller's publications include "Echoes of Sophocles's Antigone in Auster's Invisible," CLCWeb: Comparative Literature and Culture (2011). E-mail: <h0991224@hku.hk>. 